\title{
Editorial for the Inaugural Issue: Grande Medical Journal (GMJ)
}

We are proud and honored to launch the inaugural issue of our new academic endeavor - Grande Medical Journal (GMJ), published by Academic \& Research Department, Grande International Hospital (GIH).

GMJ is an annual, open, peer-reviewed interdisciplinary journal that encompasses all fields of medicine and clinical practice. GMJ will be published both in print and online. It will be freely accessible via the internet through GIH's website with open access to the full text of articles. There will be no subscription fees to the readers or processing fees for the authors. Publisher and authors who publish in the journal will jointly retain the copyright to their article.

The editorial policy of GMJ will be guided by the high standards of scientific quality and integrity, professional responsibility, and ethical legacy. GMJ follows double-blind peer-review process. This minimizes the possibility of a biased opinion ensuring a responsible and ethical environment.

GMJ will be initially published as one issue per year, and with contributions from national and international physicians and scientists, we aim to increase the frequency to two issues per year. GMJ will publish original research, clinical review, invited reviews, case report, clinical problem solving, clinical images, short communications, and editorials.

This inaugural issue features fifteen scientific papers - 1 invited review, 3 original researches, 2 clinical reviews, 1 clinical images article, 8 case reports. The editorial board is committed to get the journal indexed in major search engines, indices, and databases to increase their visibility/ searchability and recognition in wider scientific community. For us to achieve these goals, in the forthcoming issues we seek to publish original, high-quality, peerreviewed papers including original clinical and editorials, clinical reviews, and correspondence on matters that will provide comprehensive coverage on all aspects and subspecialties of medicine.

We would like to thank everyone who has worked diligently behind the scenes to bring this inaugural issue to fruition. This launch of the GMJ would not have been possible without the contributions from authors, and experienced and devoted reviewers who willingly signed up for timeconsuming workloads and enthusiastically agreed to provide their critical input to the review process.

Thank you all for your trust and support. Indeed, it is a real honor to serve as the founding editors.

Sincerely Yours,

Prakash Kafle, MS

Editor-in-Chief 